Chapter 15

\title{
Antioxidants in Decelerating Diabetic Nephropathy
}

\author{
Wen-Chin Lee, Chau-Jong Wang and Huei-Jane Lee
}

Additional information is available at the end of the chapter

http://dx.doi.org/10.5772/45927

\section{Introduction}

Diabetes mellitus (DM) is a group of metabolic diseases characterized with inappropriate hyperglycemia due to either a deficiency of insulin secretion or a combination of insulin resistance and inadequate insulin secretion (Masharani, 2008). Type 1 diabetes is caused by absolute deficiency of insulin secretion. Individuals at risk of developing this type of diabetes are found with serologic evidence of an autoimmune process occurring in the pancreatic islets and by genetic markers. In type 2 diabetes, it is a combination of resistance to insulin action and an inadequate compensatory insulin secretion response (American Diabetes Association, 2008). Diabetic nephropathy, one of the common complications of diabetes, has become the leading cause of end-stage renal failure in many countries (Chen et al., 2005). In general, about 1 out of 3 patients with type 1 or type 2 diabetes proceed to developing significant diabetic nephropathy (Zipp and Schelling, 2003). It is believed that the pathophysiologic mechanisms of renal disorder are similar in both types of diabetes (Kern et al., 1999). The pathogenesis and clinical course of diabetic nephropathy can be monitored by structural and hemodynamic changes. The earliest changes is an increase in glomerular filtration rate (GFR), also call "hyperfiltration" stage, which is followed by detectable glomerular lesions with normal albumin excretion rate. The next change is the development of microalbuminuria. Once microalbuminuria persist, both changes in glomerular structure, such as mesangial expansion and basement membrane thickening, and permeability happened, which is referred as "incipient nephropathy". Diabetic subjects with persistent microalbuminuria are at increased risk for "overt diabetic nephropathy". At this stage, prominent proteinuria, hypertension, and renal insufficiency progressed. The pathological findings in this stage are glomerular basement membrane (GBM) thickening, mesangial expansion and resulting in diffuse and/or nodular glomerulosclerosis, afferent and efferent arteriolar hyalinosis, and tubulointerstitial fibrosis (Cooper and Gilbert, 2003). After several years of persistent proteinuria, progression to end-stage renal disease will occur (Caramori and Mauer, 2001). 
Advanced diabetic glomerulopathy is commonly characterized by diffuse glomerulosclerosis and may sometimes exhibit a distinctive morphological appearance, namely, the nodular form of glomerulosclerosis, as first described by Kimmelstiel and Wilson in 1936 (Kimmelstiel and Wilson, 1936; Kern et al., 1999). The stages of diabetic nephropathy are shown in Table 1 (Vora and Ibrahim, 2003).

\begin{tabular}{ll}
\hline Stage & Renal manifestation \\
\hline 1 & Renal hyperfiltration (GFR $\uparrow)$ \\
& Renal hypertrophy \\
& Silent stage \\
& Renal hyperfiltration (GFR* $\uparrow) ;$ Normal UAER*, blood pressure \\
& Early histologic changes: non-specific increase in basement membrane thickness, increase \\
& mesangial matrix \\
& Microalbuminuria (UAER 30-300mg/24 h) or incipient nephropathy \\
& GFR may elevated or reduced into normal range. \\
& Histology: mesangial expansion, glomerular basement membrane thickening, arteriolar hyalinosis \\
& Established or overt nephropathy (Proteinuria, nephrotic syndrome) \\
& GFR decline, Hypertension \\
& Histology: mesangial nodules (Kimmelstiel-Wilson lesions), tubulointerstitial fibrosis \\
& ESRD***
\end{tabular}

Table 1. Natural course of diabetic nephropathy in type 1 diabetes

The current strategies to treat diabetic nephropathy include intensive glycemic control, antihypertensive treatment with a particular focus on the interruption of renin-angiotensin-aldosterone system (RAS), restriction of dietary protein, and treatment of hyperlipidemia. There are several new approaches to the treatment of diabetic nephropathy based on an ever-growing mechanistic understanding of the causes of diabetic nephropathy by the specific pathogenic roles. These agents include pharmacologic inhibitors of advanced glycation end products (AGEs) formation, protein kinase C (PKC), oxidative stress, and transforming growth factor $\beta$ (TGF- $\beta$ ) (Williams and Stanton, 2005).

\section{Animal models of diabetes mellitus}

Type 1 diabetes mellitus is typically an immune mediated destruction of the pancreatic 
$\beta$ cells. Type 2 diabetes mellitus is characterized by insulin resistance and insulin secretion impairment. Animal models have been used extensively in the field of diabetes study. The current available animal models of type 1 and type 2 diabetes are shown in Table 2 (Rees and Alcolado, 2005).

\begin{tabular}{ll}
\hline Type 1 & BB (Bio breeding) rat \\
& Chinese hamster \\
& Celebes black ape \\
& Keeshond dog \\
& LETL (Long Evans Tokushima lean) rat \\
& New Zeland white rabbit \\
& NOD (non-obese diabetic) mouse \\
& Streptozotocin-induced rats \\
& CBA/Ca mouse \\
& db/db mouse \\
Diabetic Torri rat \\
GK (GotoKakizaki) rat \\
Israeli sand rat \\
KK mouse \\
New Zeland obese mouse \\
NSY (Nagoya-Shibata-Yasuda) mouse \\
Ob/Ob mouse \\
OLETF (Otsuka Long-Evans Tokushima fatty) rat \\
Zucker rat \\
\hline
\end{tabular}

Table 2. Animal models of type 1 and 2 diabetes mellitus

\section{The molecular mechanism of oxidative stress in diabetic nephropathy}

There are four major biochemical pathways considered to lead to the development of diabetic complications associated with hyperglycemia, (1) the polyol pathway, glucose is converted to sorbitol and then metabolized to fructose. Advanced glycation end products (AGE) and reactive oxygen species (ROS) formation also occurs via this pathway, (2) the hexosamine pathway, fructose-6-phosphate is converted to glucosamine intermediates and the production of ROS is subsequently increased, (3) the protein kinase C (PKC) pathway, glucose is converted to glyceraldehyde-3-phosphate and leads to the formation of diacylglycerol (DAG). The elevation of intracellular DAG levels activate PKC, and then activate NADPH oxidase to induce ROS, (4) the formation of advanced glycation end products (AGEs), interaction of AGEs with the receptors of advanced glycation end-products (RAGE) results in ROS activation (Stirban et al., 2008; Shah et al., 2009; Forbes et al., 2008; Brownlee, 2005; Kanwar et al., 2008; Singh et al., 2011). 
Increased oxidative stress has been a widely accepted participant in the development and progression of diabetes and its complications (Maritim et al., 2003). ROS are activated in glomerular mesangial and tubular epithelial cells by high glucose, AGE, and cytokines (Park et al., 1999). Hyperglycemia activates the glycolytic pathway and excess generation of mitochondrial ROS initiates a vicious circle by activating several signaling to increase protein kinase $\mathrm{C}$ (PKC), and stimulating NADPH oxidase to induce ROS generation (Johansen et al., 2005). Free radicals has been found to be formed disproportionately increase in diabetic subjects by glucose oxidation, nonenzymaticglycation of proteins, and then oxidative degradation of glycated proteins. Excessively amount of free radicals induce damage to cellular proteins, membrane lipids, nucleic acids, and then cell death (Maritim et al., 2003). Besides, increased ROS can cause vascular endothelium abnormalities, reacting directly with nitric oxide (NO) to produce cytotoxic peroxynitrite and increasing reactivity to vasoconstrictors and modification of extracellular matrix proteins (Schnackenberg, 2002). ROS can also damage endothelial cells indirectly by stimulating expression of various genes involved in inflammatory pathway (Baldwin, 1996). Previous study finds that high glucose induces ROS and then up-regulates TGF- $\beta 1$ and extracellular matrix (ECM) expression in the glomerular mesangial cell (Lee et al., 2003). There are also evidences that antioxidants can effectively inhibit high glucose induced TGF- $\beta 1$ and fibronectin up-regulation (Ha et al., 1997). Ha et al. (2002) reported that ROS mediate high glucose-induced activation of NF- $\kappa \mathrm{B}$ and NF- $\kappa \mathrm{B}$ dependent monocyte chemoattractant protein (MCP)-1 expression. NF- $\kappa \mathrm{B}$, a nuclear transcription factor, can initiate the transcription of genes associated with inflammatory response. It is induced by various cell stress-associated stimuli including growth factors, vasoactive agents, cytokines, and oxidative stress (Kuhad and Chopra, 2009). Advanced glycation end products induced by hyperglycemia stimulate NF- $\kappa B$ activation, which sustains the activation of NF- $\kappa B$ in diabetes (Gao et al., 2006). Increased steady-state mRNA levels of inflammatory genes have been shown to associate with interstitial fibrosis and progressive human diabetic nephropathy (Kuhad and Chopra, 2009).

TGF- $\beta$ plays an important role in the development of renal hypertrophy and accumulation of extracellular matrix (ECM) components in diabetes mellitus (Wolf and Ziyadeh, 1999). The expression of TGF- $\beta$ was found increased in diabetic nephropathy of experimental animals and in humans (Park et al., 1997; Yamamoto et al., 1993; Sharma et al., 1997; Shankland et al., 1994). Treatment with anti-TGF- $\beta$ antibody has been documented that it attenuated the effect of high glucose induced cellular hypertrophy in vitro and in streptozotocin-induced diabetic mice (Wolf et al., 1992; Ziyadeh et al., 1994; Sharma et al., 1996). TGF- $\beta$ is also the key regulator of ECM remodeling in mesangium causing mesangial expansion and inducing the process of epithelial-mesenchymal transition (EMT) causing tubulointerstitial fibrosis (Ziyadeh et al., 2000; Oldfield et al., 2001). As the accumulation of ECM and persistence of tubulointerstitial fibrosis, the renal function progress to end-stage renal disease (ESRD). The relation between oxidative stress and diabetic nephropathy are shown in Figure 1 (Shah et al, 2007). 


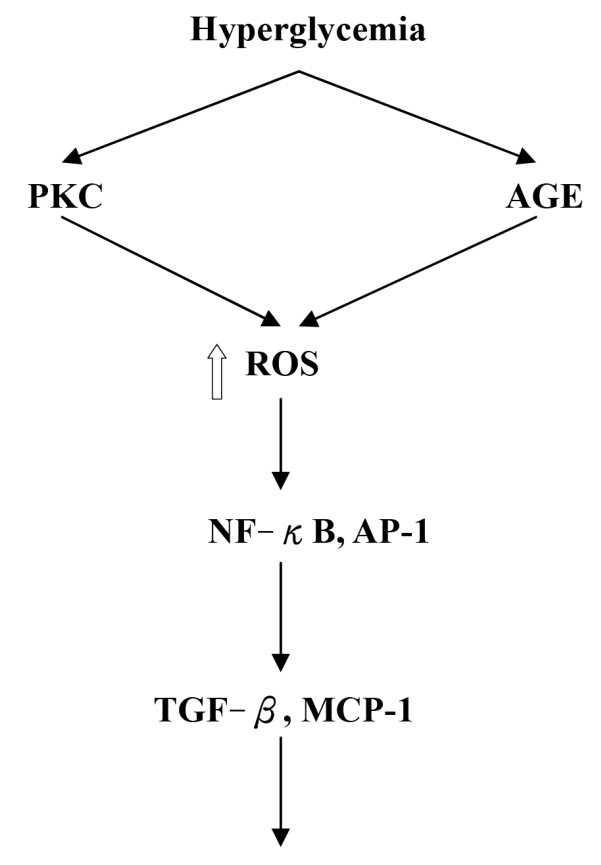

Diabetic nephropathy progression

Figure 1. The relation between oxidative stress and diabetic nephropathy* ${ }^{*} P K C$, protein kinase $C ; A G E$, advanced glycation end products; ROS, reactive oxygen species; NF-KB, nulcear factor-kappa B; AP-1,activator protein-1; TGF- $\beta$, transforming growth factor-beta; MCP-1, monocyte chemotactic protein-1

\section{Improvement of antioxidantive status in diabetic nephropathy}

There are many evidences suggest that ROS play an important role in the pathogenesis of diabetic nephropathy (Rosen et al., 2001). To prevent the development and progression of diabetic nephropathy, it would be effective in combing the strategies to prevent overproduction of ROS and to increase the removal of preformed ROS. (Ha et al., 2008). Some natural products were proved to possess the ability to decelerate diabetic nephropathy via reducing oxidative status. The flower of Hibiscus sabdariffaLinnaeus calyx (family Malvaceae, local name Karkaday) is commonly used in cold and hot beverages and as a supplement due to its perceived potential of health benefits. The flower extract has been reported to decrease blood pressure, and have antitumor characteristics as well as immune-modulating and antileukemic effects (Haji Faraji and Haji Tarkhani, 1999; Tseng et al., 2000). Hibiscus sabdariffaL. extract contains polyphenolic acids, flavonoids, protocatechuic acid (PCA) and anthocyanins. Hibiscus sabdariffaL. extract has been found to contain various polyphenols and was shown to have antioxidative potential to inhibit the development of atherosclerosis in cho- 
lesterol-fed rabbits, LDL oxidation and ox-LDL-mediated macrophage apoptosis (Chen et al., 2003; Chang et al., 2006). Wang et al. (2009) demonstrated that aqueous extract of Hibiscus sabdariffa L. (HSE) is capable of increasing catalase and glutathione activities significantly in diabetic kidney. In histological examination, HSE improves hydropic change of renal proximal convoluted tubules in diabetic rats. HSE was also revealed to up-regulate Akt/Bad/ 14-3-3 ' and NF-kB-mediated transcription in diabetic nephropathy. Luteolin is a plant-derived flavonoid, it has various biological activities including anti-inflammatory (Jang et al., 2008), antimutagenic, and antitumorigenic properties (Ross and Kasum, 2002). It also possesses direct antioxidant activity (L'opez-L'azaro, 2009), and may be useful in treatment of many chronic disease associated with oxidative stress, such as cardiovascular diseases (McCord, 1985; Jeroudi et al., 1994), liver diseases (Comporti, 1985; Poli et al., 1987), diabetes (Oberley, 1988), and aging (Harman, 1981). Wang et al. (2011) demonstrated that luteolin has protecting effect against development of diabetic nephropathy by changing the superoxide dismutase (SOD) activity, the malondialdehyde (MDA) content, and expression of Heme Oxygenase-1 (HO-1) protein.

On the other hand, some evidences show the exogenous or endogenous antioxidants also can reduce diabetic nephropathy. Oxidative stress via nicotinamide adenine dinucleotide phosphate (NADPH) oxidase and vascular endothelial growth factor (VEGF) pathway are documented to play important roles in the development of diabetic nephropathy. Nam et al. (2009) showed the effects of apocynin, a NADPH oxidase inhibitor, on diabetic nephropathy. They found that apocynincan not significantly decrease serum glucose levels but reduce urinary protein and albumin excretions. It is improved in glomerular and mesangial expansion as the apocynin treatment. Apocynin also decreased glomerular VEGF expression and reduced the concentration of $24 \mathrm{~h}$ urinary 8-OHdG and MDA. Additionally, Lee et al. (2005) demonstrated that antioxidant taurine prevented glomerular hypertrophy, mesangial expansion, and proteinuria in diabetic rats. Overexpression of catalytic antioxidants was also shown to protect against diabetic injury in several transgenic animals. Craven et al. (2001) showed that diabetic mice transgenic for $\mathrm{Cu} / \mathrm{Zn} \mathrm{SOD}$ had significantly lower urinary albumin excretion, glomerular hypertrophy, and glomerular expression of TGF- $\beta 1$ and collagen IV protein compared to non-transgenic mice. Hamada et al. (2007) demonstrated that overexpression a small antioxidant, thioredoxin 1, effectively inhibited 8-OHdG in the kidney, albuminuria, mesangial expansion, and tubular injury in diabetic mice. Du et al. (2003) found that overexpression of MnSOD in bovine aortic endothelial cells prevented high glucose-induced activation of PKC, NK-kB, hexosamine, and advanced glycation end product (AGE) pathways. Brezniceanu et al. (2007) demonstrated that renal catalase overexpression in $\mathrm{db} / \mathrm{db}$ mice attenuated ROS generation, angiotensinogen, proapoptotic gene expression and apoptosis in the kidneys of diabetic mice in vivo.

Although strict glycemic control is very important in DM patients, many of the current standard therapeutic approaches may also ameliorate oxidative stress as pleiotropic effects (Singh et al., 2011), such as angiotensin-2 converting enzyme (ACE) inhibitors(Kobayashi et al., 2006), angiotensin-2 receptor blockers (ARB) (Ogawa et al., 2006) and aldosterone blockers (spironolactone) (Takebayashi et al., 2006). They activate eNOS to increase bioavailability 
of nitric oxide, inhibit synthesis of angiotensin 2 and TGF- $\beta$ and to decelerate or prevent tubulointerstitial fibrosis in diabetic nephropathy, accompanied with control of systemic and intrarenal blood pressure. Cilostazol is a specific inhibitor of phosphodiesterase 3 (PDE 3). Its major effects are prevention of platelet aggregation and dilation of blood vessels via an increase in tissue cAMP levels (Matsumoto et al., 2005). Cilostazol was shown to inhibit vascular smooth muscle cell proliferation in vitro as well as suppress neointimal formation in balloon-injured rat carotid arteries due to its antiplatelet and vasodilator properties (Takahashi et al., 1992; Ishizaka et al., 1999). Our previous study showed that cilostazol decreases reactive oxygen species activity significantly in the kidneys of diabetic rats and improves urine albumin/creatinine ratio. Cilostazol also can improve the diabetes-caused increasing glomerular size, TGF- $\beta$, and NF-kB in early diabetic nephropathy (Lee et al., 2010). The lipid-lowering agents such as statins, which can inhibit HMG-CoA reductase to be demonstrated to activate eNOS, maintain glomerular filtration rate and renal cortical blood flow, and further to ameliorate glomerular lesions(Usui et al., 2003; Endres and Laufs, 2004). Benfotiamine was used in the treatment of diabetic nephropathy, it was also demonstrated to reduce ROS formation and may decrease hyperfiltration and proteinuria in patients with diabetic nephropathy(Babaei-Jadidi et al., 2003). Potential therapies in these ideal antioxidants would influence the pathways of ROS generation to decelerate diabetic nephropathy.

\section{Author details}

Wen-Chin Lee ${ }^{1,2^{*}}$, Chau-Jong Wang ${ }^{3}$ and Huei-Jane Lee ${ }^{3}$

1 Division of Nephrology, Department of Internal Medicine, Show Chwan Memorial Hospital, Changhua, Taiwan

2 General Education Center, Central Taiwan University of Science and Technology, Taichung, Taiwan

3 Institute of Biochemistry and Biotechnology, Medical College, Chung Shan Medical University, Taichung, Taiwan

\section{References}

[1] American Diabetes Association(2008). Diagnosis and classification of diabetes mellitus.Diabetes Care31: SS60., 55.

[2] Babaei-Jadidi, R., Karachalias, N., Ahmed, N., Battah, S., \& Thornalley, P. J. (2003). Prevention of incipient diabetic nephropathy by high-dose thiamine and benfotiamine. Diabetes, 52, 2110-2120.

[3] Baldwin AS Jr(1996). The NF-KB and IKB proteins: new discoveries and insights. Annu Rev Immunol, 14, 649-683. 
[4] Brezniceanu, M. L., Liu, F., Wei, C. C., Tran, S., Sachetelli, S., Zhang, S. L., Guo, D. F., Filep, J. G., Ingefinger, J. R., \& Chan, J. S. (2007). Catalase overexpression attenuates angiotensinogen expression and apoptosis in diabetic mice. Kidney Int, 71, 912-923.

[5] Brownlee, M. (2005). The pathobiology of diabetic complications: a unifying mechanism. Diabetes, 54, 1615-1625.

[6] Caramori, M. L., \& Mauer, M. (2001). Diabetic nephropathy. in Primer on kidney diseases, $3^{\text {rd }}$ edition (Greenberg A, Cheung AK, Coffman TM, Falk RJ, and Jennette JC eds) National Kidney Fundation, Florida., 212-218.

[7] Chang YC, Huang KX, Huang AC, Ho YC, and Wang CJ(2006). Hibiscus anthocyanins- rich extract inhibited LDL oxidation and oxLDL-mediated macrophages apoptosi. s. Food ChemToxicol, 44, 1015-1023.

[8] Chen CC, Hsu JD, Wang SF, Chiang HC, Yang MY, Kao ES, Ho YC, and Wang $\mathrm{CJ}(2003)$. Hibiscus sabdariffaExtract inhibits the development of atherosclerosis in cholesterol-fed rabbits. J Agric Food Chem, 51, 5472-5477.

[9] Chen HC, Guh JY, Chang JM, Hsieh MC, Shin SJ, and Lai YH(2005). Role of lipid control in diabetic nephropathy. Kidney IntSupp194: SS62., 60.

[10] Comporti, M. (1985). Lipid peroxidation and cellular damage in toxic liver injury.Lab Invest, 53, 599-623.

[11] Cooper ME, and Gilbert RE(2003). Pathogenesis, prevention, and treatment of di. abetic nephropathy, In Comprehensive clinical nephrology $2^{\text {nd }}$ edition (Johnson RJ, and Feehally J, eds) Mosby, Edinburgh., 439-450.

[12] Craven PA, Melhem MF, Phillips SL, and DeRubertis FR. (2001). Overexpression of $\mathrm{Cu} 2+/ \mathrm{Zn} 2+$ superoxide dismutase protects against early diabetic glomerular injury in transgenic mice. Diabetes, 50, 2114-2125.

[13] Du, X., Matsumura, T., Edelstein, D., Rossetti, L., Zsengelle', r. Z., Szabo', C., \& Brownlee, M. (2003). Inhibition of GAPDH activity by poly(ADP-ribose) polymerase activates three major pathways of hyperglycemic damage in endothelial cells. J Clin Invest, 112, 1049-1057.

[14] Endres, M., \& Laufs, U. (2004). Effects of statins on endothelium and signaling mechanisms. Stroke35 (Suppl 1): , 2708 EOF-11 EOF.

[15] Forbes JM, Coughlan MT, and Cooper ME. (2008). Oxidative stress as a major culprit in kidney disease in diabetes. diabetes, 1446-1454.

[16] Gao, L., Wang, F., Wang, B., Gong, B., Zhang, J., Zhang, X., \& Zhao, J. (2006). Cilostazol protects diabetic rats from vascular inflammation via nuclear factor-KB-dependent down-regulation of vascular cell adhesion molecule-1 expression. J PharmacolExpTher, 318, 53-58.

[17] Ha, H., Lee, S. H., \& Kim, K. H. (1997). Effects of rebamipide in a model of experimental diabetes and on the synthesis of transforming growth factor- $\beta$ and fibronec- 
tin, and lipid peroxidation induced by high glucose in cultured mesangial cells. J PharmacolExpTher, 281, 1457-1462.

[18] Ha, H., Yu, M. R., Choi, Y. J., Kitamura, M., \& Lee, H. B. (2002). Role of high glucoseinduced nuclear factor-KB activation in monocyte chemoattractant protein-I expression by mesangial cells. J Am SocNephrol, 13, 894-902.

[19] Ha, H., Hwang, I. A., Park, J. H., \& Lee, H. B. (2008). Role of reactive oxygen species in the pathogenesis of diabetic nephropathy. Diabetes Res ClinPract82 Suppl 1: S, $42-5$.

[20] Haji, Faraji. M., \& Haji, Tarkhani. A. (1999). The effect of sour tea (Hibiscus sabdariffa) on essential hypertension. J Ethnopharmacol, 65, 231-236.

[21] Hamada, Y., Miyata, S., Nii-Kono, T., Kitazawa, R., Kitazawa, S., Higo, S., Fukunaga, M., Ueyama, S., Nakamura, H., Yodoi, J., Fukagawa, M., \& Kasuga, M. (2007). Overexpression of thioredoxin1 in transgenic mice suppresses development of diabetic nephropathy. Nephrol Dial Transplant, 22, 1547-1557.

[22] Harman, D. (1981). The aging process. ProcNatlAcadSci USA, 78, 7124-7128.

[23] Ishizaka, N., Taguchi, J., Kimura, Y., Ikari, Y., Aizawa, T., Togo, M., Miki, K., Kurokawa, K., \& Ohno, M. (1999). Effects of a single local administration of cilostazol on neointimal formation in balloon-injured rat carotid artery. Atherosclerosis, 142, 41-46.

[24] Jang, S., Kelley, K. W., \& Johnson, R. W. (2008). Luteolin reduces IL-6 production in microglia by inhibiting JNK phosphorylation and activation of AP-1. ProcNatlAcadSci USA, 105, 7534-7539.

[25] Jeroudi, M. O., Hartley, C. J., \& Bolli, R. (1994). Myocardial reperfusion injury: role of oxygen radicals and potential therapy with antioxidants. Am J Cardiol73: , 2B EOF-7B EOF.

[26] Johansen, J. S., Harris, A. K., Rychly, D. J., \& Ergul, A. (2005). Oxidative stress and the use of antioxidants in diabetes: linking basic science to clinical practice. CardiovascDiabetol4: 5 .

[27] Kanwar, Y. S., Wada, J., Sun, L., Xie, P., Wallner, E. I., Chen, S., Chugh, S., \& Danesh, F. R. (2008). Diabetic nephropathy: mechanisms of renal disease progression. ExpBiol Med, 233, 4-11.

[28] Kern, W. F., Laszik, Z. G., Nadasdy, T., Silva, F. G., Bane, B. L., \& Pitha, J. V. (1999). The kidney in metabolic disorder-- diabetes mellitus, hyperuricemia, oxalosis, nephrocalcinosis, and nephrolithiasis. in Atlas of renal pathology ( Kern WF, Laszik ZG, Nadasdy T, Silva FG, Bane BL, and Pitha JV, eds) W.B. Saunders company, Philadelphia., 97-112.

[29] Kimmelstiel, P., \& Wilson, C. (1936). Intercapillary lesions in glomeruli of the kidney. Am. J Pathol, 12, 83-97. 
[30] Kobayashi, N., Honda, T., Yoshida, K., Nakano, S., Ohno, T., Tsubokou, T., Matsuoka, H., \& (200, . (2006). Critical role of bradykinin-eNOS and oxidative stress-LOX-1 pathway in cardiovascular remodeling under chronic angiotensin-converting enzyme inhibition. Atherosclerosis, 187, 92-100.

[31] Kuhad, A., \& Chopra, K. (2009). Attenuation of diabetic nephropathy by tocotrienol: involvement of NF-KB signaling pathway. Life Sci, 84, 296-301.

[32] Lee, E. A., Seo, J. Y., Jiang, Z., Yu, M. R., Kwon, M. K., Ha, H., \& Lee, H. B. (2005). Reactive oxygen species mediate high glucose-induced plasminogen activator inhibitor-1 upregulation in mesangial cells and in diabetic kidney. Kidney Int, 67, 1762-1771.

[33] Lee, H. B., Yu, M. R., Yang, Y., Jiang, Z., \& Ha, H. (2003). Reactive oxygen speciesregulated signaling pathways in diabetic nephropathy.J Am SocNephrol14: S, 241-245.

[34] Lee, W. C., Chen, H. C., Wang, C. Y., Lin, P. Y., Ou, T. T., Chen, C. C., Wen, M. C., Wang, J., \& Lee, H. J. (2010). Cilostazol ameliorates nephropathy in type 1 diabetic rats involving mprovement of oxidative stress and regulation of TGF- $\beta$ and NF-B.BiosciBiotechnolBiochem, 74, 1355-1361.

[35] L'opez-L'azaro, M. (2009). Distribution and biological activities of the flavonoid luteol in Mini Rev Med Chem, 9, 31-59.

[36] Maritim AC, Sanders RA, and Watkins JB $3^{\text {rd }}$ (2003). Diabetes, oxidative stress, and antioxidants: A review. J BiochemMolToxicol, 17, 24-38.

[37] Masharani, U. (2008). Diabetes Mellitus and hypoglycemia, in Current medical diagnosis and treatment, 47. th edition (McPhee SJ, Papadakis MA, and Tierney LM, eds), McGraw-Hill, New York., 1032-1073.

[38] Matsumoto, T., Kobayashi, T., Wakabayashi, K., \& Kamata, K. (2005). Cilostazol improves endothelium-derived hyperpolarizing factor-type relaxation in mesenteric arteries from diabetic rats. Am J Physiol Heart CircPhysiol289: HH1940., 1933.

[39] McCord JM(1985). Oxygen-derived free radicals in postischemic tissue injury. N Engl J Med, 312, 159-163.

[40] Nam SM, Lee MY, Koh JH, Park JH, Shin JY, Shin YG, Koh SB, Lee EY, and Chung $\mathrm{CH}(2009)$. Effects of NADPH oxidase inhibitor on diabetic nephropathy in OLETF rats: The role of reducing oxidative stress in its protective property. Diabetes Res ClinPract, 83, 176-182.

[41] Oberley LW(1988). Free radicals and diabetes.Free RadicBiol Med, 5, 113-124.

[42] Ogawa, S., Mori, T., Nako, K., Keto, T., Takeuchi, K., \& Ito, S. (2006). Angiotensin II type 1 receptor blockers reduce urinary oxidative stress markers in hypertensive diabetic nephropathy. Hypertension, 47, 699-705. 
[43] Oldfield, Bach. L. A., Forbes, J. M., Nikolic-Paterson, D., Mc Robert, A., Thallas, V., Atkins, R. C., Osicka, T., Jerums, G., \& Copper, . (2001). Advanced glycation end products cause epithelial-myofibroblast transdifferentiation via the receptor for advanced glycation end products (RAGE). J Clin Invest, 108, 1853-1863.

[44] Park, I. S., Kiyomoto, H., Abboud, S. L., \& Abboud, H. E. (1997). Expression of transforming growth factor- $\beta$ and type IV collagen in early streptozotocin- induced diabetes. Diabetes, 46, 473-480.

[45] Park JY, Ha SW, and King GL(1999). The role of protein kinase C activation in the pathogenesis of diabetic vascular complications.Perit Dial Int19: SS227., 222.

[46] Poli, G., Albano, E., \& Dianzani, M. U. (1987). The role of lipid peroxidation in liver damage. ChemPhys Lipids, 45, 117-142.

[47] Rees DA and Alcolado JC(2005). Animal models of diabetes mellitus. Diabet Med, $22,359-370$.

[48] Ro ${ }^{\circ}$, sen. P., Nawroth, P. P., King, G., $\mathrm{Mo}^{\circ}$, ller. W., Tritschler, H. J., \& Packer, L. (2001). The role of oxidative stress in the onset and progression of diabetes and its complications: a summary of a Congress Series sponsored by UNESCO-MCBN, the American Diabetes Association and the German Diabetes Society. Diabetes Metab Res Rev, 17, 189-212.

[49] Ross JA, and Kasum CM(2002). Dietary flavonoids: bioavailability, metabolic effects, and safety. Annu Rev Nutr, 22, 19-34.

[50] Schnackenberg CG(2002). Physiological and pathophysiological roles of oxygen radicals in the renal microvasculature.Am J PhysiolRegulIntegr Comp Physiol282: RR342., 335.

[51] Shah IM, Mackay SP, and McKay GA(2009). Therapeutic strategies in the treatment of diabetic nephropathy- a translational medicine approach. Curr Med Chem, 16, 997-1016.

[52] Shah, S. V., Baliga, R., Rajapurkar, M., \& Fonseca, V. A. (2007). Oxidants in chronic kidney disease. J Am SocNephrol, 18, 16-28.

[53] Shankland, S. J., Scholey, J. W., Ly, H., \& Thai, K. (1994). Expression of transforming growth factor- $\beta 1$ during diabetic renal hypertrophy.Kidney Int, 46, 430-442.

[54] Sharma, K., Jin, Y., Guo, J., \& Ziyadeh, F. N. (1996). Neutralization of TGF-beta by anti-TGF-beta antibody attenuates kidney hypertrophy and the enhanced extracellular matrix gene expression in STZ-induced diabetic mice. Diabetes, 45, 522-530.

[55] Sharma, K., Ziyadeh, F. N., Alzahabi, B., Mc Gowan, T. A., Kapoor, S., Kurnik, B. R., Kurnik, P. B., \& Weisberg, L. S. (1997). Increased renal production of transforming growth factor-beta 1 in patients with type II diabetes. Diabetes, 46, 854-859.

[56] Singh, D. K., Winocour, P., \& Farrington, K. (2011). Oxidative stress in early diabetic nephropathy: fueling the fire. Nat Rev Endocrinol, 7, 176-184. 
[57] Stirban, A., Rosen, P., \& Tschoepe, D. (2008). Complications of type 1 diabetes: new molecular findings. Mt Sinai J Med, 75, 328-351.

[58] Takahashi, S., Oida, K., Fujiwara, R., Maeda, H., Hayashi, S., Takai, H., Tamai, T., Nakai, T., \& Miyabo, S. (1992). Effect of cilostazol, a cyclic AMP phosphodiesterase inhibitor, on the proliferation of rat aortic smooth muscle cells in culture. J Cardiovasc Pharmacol , 20, 900-906.

[59] Takebayashi, K., Matsumoto, S., Aso, Y., \& Inukai, T. (2006). Aldosterone blockade attenuates urinary monocyte chemoattractant protein-1 and oxidative stress in patients with type 2 diabetes complicated by diabetic nephropathy. J Clin Endocrinol Metab , 91, 2214-2217.

[60] Tseng TH, Kao TW, Chu CY, Chou FP, Lin WL, and Wang CJ(2000). Induction of apoptosis Hibiscus protocatechuic acid in human leukemia cells via reduction of retinoblastoma (RB) phosphorylation and Bcl-2 expression. Bi. ochemPharmacol, 60, 307-315.

[61] Usui, H., Shikata, K., Matsuda, M., Okada, S., Ogawa, D., Yamashita, T., Hida, K., Satoh, M., Wada, J., \& Makino, H. (2003). HMG-CoA reductase inhibitor ameliorates diabetic nephropathy by its pleiotropic effects in rats. Nephro. Dial Transplant, 18, 265-272.

[62] Vora JP, and Ibrahim HAA(2003). Clinical manifestations and natural history of diabetic nephropathy, in Comprehensive clinical nephrology, $2^{\text {nd }}$ edition (Johnson RJ, and Feehally J, eds), Mosby, Edinburgh., 425-437.

[63] Wang, G. G., Lu, X. H., Li, W., Zhao, X., \& Zhang, C. (2011). Protective effects of luteolin on diabetic nephropathy in STZ-Induced diabetic rats. Evid Based Complement Alternat Med doi:10.1155/2011/ .

[64] Wang SC, Lee SF, Wang CJ, Lee CH, Lee WC, and Lee HJ(2009). Aqueous Extract from Hibiscus sabdariffa Linnaeus Ameliorate Diabetic Nephropathy via Regulating Oxidative Status and Akt/Bad/14-3-3\{gamma\} in an Experimental Animal Model. eCAM 10.1093/ecam/nep181.

[65] Williams ME, and Stanton RC(2005). Management of diabetic kidney disease, in Joslin's Diabetes Mellitus (Kahn CR, Weir GC, King GL, Jacobson AM, Moses AC, and Smith RJ, eds) Lippincott Williams \& Wilkins, Philadelphia., 925-949.

[66] Wolf, G., Sharma, K., Chen, Y., Ericksen, M., \& Ziyadeh, F. N. (1992). High glucoseinduced proliferation in mesangial cells is reversed by autocrine TGF- $\beta$. Kidney Int, 42, 647-656.

[67] Wolf, G., \& Ziyadeh, F. N. (1999). Molecular mechanisms of diabetic renal hypertrophy. Kidney Int, 56, 393-405.

[68] Yamamoto, T., Nakamura, T., Noble, N. A., Ruoslahti, E., \& Border, W. A. (1993). Expression of transforming growth factor- $\beta$ is elevated in human and experimental diabetic nephropathy. ProcNatlAcadSci USA, 90, 1814-1818. 
[69] Zipp, T., \& Schelling, J. R. (2003). Diabetic nephropathy, in Nephrology secrets $2^{\text {nd }}$ edition (Hricik DE, Miller RT, Sedor JR, eds) Hanley \&Belfus Inc. Medical Publishers, Philadelphia., 105-111.

[70] Ziyadeh, F. N., Hoffman, B. B., Han, D. C., Iglesias La, Cruz. M. C., Hong, S. W., Isono, M., Chen, S., Mc Gowan, T. A., \& Sharma, K. (2000). Long-term prevention of renal insufficiency, excess matrix gene expression, and glomerular mesangial matrix expansion by treatment with monoclonal anti-transforming growth factor-beta antibody in db/db diabetic. mice. ProcNatlAcadSci USA, 97, 8015-8020.

[71] Ziyadeh, F. N., Sharma, K., Ericksen, M., \& Wolf, G. (1994). Stimulation of collagen gene expression and protein synthesis in murine mesangial cells by high glucose is mediated by activation of transforming growth factor- $\beta$. J Clin Invest , 93, 536-542. 
